\title{
A Comparison of Two Forms of Instruction: Pre-Recorded Video Lectures vs. Live ZOOM Lectures for Education in the Business Management Field
}

\author{
Maidul Islam ${ }^{1, *}$, Dan-A. Kim ${ }^{2}$ (D) and Minjoo Kwon ${ }^{2}$ \\ 1 Department of E-Trade, Keimyung University, Dalseo-gu, Daegu 42601, Korea \\ 2 East Asia International College, Yonsei University, Wonju, Gangwon-do 26493, Korea; \\ dkim123@yonsei.ac.kr (D.-A.K.); wojoo227@yonsei.ac.kr (M.K.) \\ * Correspondence: maidul@kmu.ac.kr; Tel.: +82-53-580-5967
}

Received: 17 July 2020; Accepted: 23 September 2020; Published: 2 October 2020

check for updates

\begin{abstract}
This paper employs a comparison between two forms of online instruction to investigate which form is more preferred, as well as the advantages and the disadvantages for both forms of online education. The data for the research were collected via an online questionnaire that was purposely created for the research. A sample of 26 undergraduate students of Yonsei University, South Korea, were employed for this study. Pre-tests and post-tests were performed to compare between pre-recorded video lectures and live ZOOM lectures. The results show that students prefer pre-recorded video lectures to live ZOOM lectures; $53.8 \%$ chose pre-recorded video lectures, $7.7 \%$ chose live ZOOM lectures, and 30.8\% chose both pre-recorded and ZOOM lectures when they were asked to select their preferred method of learning. Furthermore, we asked several questions, and the mean values were compared. The results of this research showed that pre-recorded video lectures are preferred to live ZOOM lectures due to their flexibility, convenience, and educational effectiveness. However, learning through video lectures depends on students' motivation to get through those materials on their own. Lack of motivation and clear deadlines to watch those video lecture materials could end up in an accumulation of workload, which would be difficult to overcome before examinations.
\end{abstract}

Keywords: business management; online education; pre-recorded lectures; ZOOM lectures; students

\section{Introduction}

With the advent of the Fourth Industrial Revolution, it seems that the educational world is also being influenced by the Information Age, in which the way humans learn will also be digitized. Though the change has been slow-paced, the recent spread of the Coronavirus, or COVID-19, has inevitably led to a drastic transition towards online classes, resulting in an urgent demand for in-depth research on effective ways to conduct and deliver online education to the public. For online classes conducted via pre-recorded video lectures, visual stimulation along with media-rich audio is a major advantage [1]. In particular, recorded lectures that are available online have functions such as 'play', 'forward', 'rewind', and 're-watch', providing students with the convenience of listening to lectures at their own speed. For this reason, online classes are expected to complement the weaknesses of long-distance classes and physical, face-to-face classes. Pre-recorded multimedia for on-demand or video conferencing have become standard methods for many to obtain information [2]. Several researchers found that pre-recorded video lectures have been given equal importance to that of written or face-to-face lectures [3,4]. Having said that, it also important to pay attention to teaching and learning strategies to provide students or learners with a quality learning environment that can 
compensate for the physical learning environment $[5,6]$. To be much more efficient and effective, educators should focus more on interactive teaching methods where students can sense social presence virtually [7]. To improve students' performance, online instructors need to be more organized and communicative [8]. Online interactive learning, such as with problem solving activities, is preferred over traditional approaches [9]. A similar conclusion was drawn by Morrison [10]. To meet these functionalities and to run interactive lectures virtually, an application called ZOOM has come into play. ZOOM is a US tech company that provides video telephony and online chat services through a P2P (Peers-to-Peer) software platform. Nowadays, ZOOM is widely used for telecommuting, distance learning, and teleconferencing around the world.

The biggest merit of live ZOOM lectures is the fact that they simulate how physical face-to-face classes are conducted. Using this form allows for more interaction between the educator and the educated. In live ZOOM lectures, students can see eye movement and hear voices; furthermore, they are enhanced by a chat function. In short, it is multimodal; students can see teachers' gestures, and teachers can see students' gestures, too. Furthermore, the ZOOM mobile app has made students rely more on smartphones and less on desktops, which can eliminate fatigue as a result of ZOOM. Several earlier research works have mentioned the successful use of live video conferencing in distance learning [2,11-13].

As we can notice, both pre-recorded video lectures and live ZOOM lectures have their own advantages and disadvantages. Therefore, this research paper examines whether pre-recorded video lectures for business major students have same effect or not in comparison to live ZOOM lectures. Do students prefer live ZOOM lectures or pre-recorded video lectures more? The purpose of the research is to find out which method of learning is more effective between pre-recorded lectures and real-time ZOOM lectures.

\section{Literature Review}

Learning achievement is greatly influenced by individual students' tendencies. At the same time, autonomous learning is greatly influenced by communication and interaction with others, which is presumed to be applied to online studies today.

"Distance education implies that the majority of educational communication between (among) teacher and student(s) occurs non-contiguously (at different times and at separate places-separating the instructor/tutor from the learner). It must involve two-way communication between (among) teacher and student(s) for the purpose of facilitating and supporting the educational process. It uses technology to mediate the necessary two-way communication" (p. 11, [14]). The research done by Makaza and Madzima [15] explored the presence of opportunities and challenges that obstruct successful implementation of e-learning technology. Classroom teaching is known to be a long-venerated teaching method, and this remains the common method of instruction in higher education around the world $[16,17]$.

Here, while the claim that online collaboration is not advantageous for all students' learning is given, the prerequisite is that there are not many research results on the use of online learning and other performance differences. However, there are also studies showing that women show a little more positive achievement in online meetings and web-based learning than men. "Nonetheless, evidence suggests that students are not homogeneous in this respect; for example, females tend to participate and benefit more from computer-conferencing than males" [18]. Similar findings have been reported among working clinicians; females adopt online continuing medical education (CME) at a faster rate [19] and tend to participate more in online CME than their male counterparts [20]. If so, how is the process of using video and multimedia materials related to the method of collaborative communication between people? According to the study of Romanov et al. [21], about one out of five medical students did not use video clips as a learning tool, and the difference between women and men when using videos was clear. The video clip's usability between genders and the activity log of students who used the video clip are given as reference materials. Women watched more videos 
than men, and the number of women students who judged that this video clip was much more useful for learning was higher than that of men. This could lead to a more objective result in connection with the fact that there was no difference in gender in computer use experience at the beginning of the study. It seems that this test led to the positive conclusion that the video is more helpful for learning. The WebCT course highlights the individual learning style under the active participation of students. In addition, in measuring the usability and value of the learning method using the video clip, experimental results considering numerous samples and variables are required. Earlier research suggested that those who have not taught or attended lectures online are more skeptical than those who have gone through the process and who are continuously open to their potential [22]. Several other researchers have explored technological implementations and practical techniques of online tools that could be effectively used to organize virtual lectures [23-25]. There are several key teaching factors that are common in teaching face-to-face and online courses; e.g., student-to-student interaction, as well as student-to-teacher interaction [26-29]. What we can learn from this is that internet-based learning systems provide students with more diverse ways of learning and become more efficient learning resources, but at the same time, these results alone cannot fully confirm the connection to learning achievement. Moreover, we also need to remember that students are from different backgrounds and may be technologically diverse [30].

An article published by Brockfeld et al. [31] explored whether lectures conducted through video have as much effect as those conducted in live courses and investigated the responses of students. The method of conducting the experiment allowed a certain percentage of students to take live lectures for a set period of time, while the remaining percentage took courses via video. They made students change their assigned lectures every day, making all students take the same online and offline classes; they then asked questions about the classes to confirm their responses to the experiment. As a result, the difference between online classes and offline classes was not great. Of course, there was a greater tendency to prefer live classes as opposed to online ones, but video courses received better reviews than live courses in some functional areas, such as "learning atmosphere" and "acoustic intelligibility". It is judged that this was due to advantages such as improving the understanding of classes by repeating lectures, saving time to attend classes, or adjusting the speed of lectures arbitrarily. "Here, the characteristics of learning atmosphere, concentration capacity, presence of other students, and the acoustical intelligibility in the video lectures are assessed significantly better than in the live lectures, but vice versa, no feature of the live lectures is assessed better than in the video lectures" [31]. In addition, they compared data from complex tests on course evaluations and concluded that live and video lectures had almost the same efficiency for the test results. In conclusion, video lectures are an effective medium for supporting the understanding of classes of students who have used existing learning approaches. A similar conclusion has been drawn by several authors [31-36], as the various forms of video instruction include multimedia and rich content. However, at the same time, these are not exceptionally good teaching methods compared to live lectures, and students favor face-to-face lectures over video lectures, as concluded by Martin et al. [36].

Ramlogan, Raman, and Sweet [37] wanted to study the achievement of dentistry students in their major field based on the learning results of online lectures and live lectures. The significance of these lectures is not just a test result, but a study based on the participants' clinical exercises. Before conducting the experiment, the authors implemented a pre-test and review in advance and confirmed that the students' learning scores were similar. Later, the authors tried to deduce the efficiency of each learning method more clearly by dividing groups of students who took live lectures and video classes, and then conducted clinical tests. Experiments on this seemed to be a useful resource for determining whether online lectures can achieve the same efficiency as live lectures for not only intellectual learning, but also behavioral learning. The conclusion of this experiment was that the live lecture has a more effective learning efficiency than the video lecture in the learning of the major. Live lectures are more interactive in nature, which allows students to interact with the learning material; this interaction may provide long-term memories to the learner $[30,38]$. Clinical 
trial learning through video lectures showed lower performance than teaching through live learning. Similar research was also done by Schreiber et al. [13] to check the efficiency of podcasts and live lectures for undergraduate medical students. Students also preferred live lectures to learn about clinical trials. However, based on the high preference for multiple learning methods, including video lectures, the results of this experiment show that live classes can provide efficient learning for behavioral learning, such as in clinical periodontology training, while at the same time, learning activities through video can be used to supplement live classes.

\section{Methods}

The main aim of the research was to explore which method of learning is more effective between pre-recorded lectures and the real-time ZOOM lectures. In this research, a pre-recorded video lecture is defined as a lecture that is recorded beforehand to be watched by students whenever they can. A live ZOOM lecture is a lecture given in real time through the digital platform called ZOOM, which enables participants to join a video conference. The target sample group included students of the East Asia International College (EIC) enrolled in the 'Quantitative Method (1)' course in the Yonsei University Mirae Campus during the first semester of 2020, which had a class size of 48 students. The subjects were given a learning objective and a written paper-based pre-test assignment (Figure 1) to make sure everyone was on the same page at the very beginning of the semester. All of these students took pre-recorded video lectures until the midterm, and then took real-time ZOOM video lectures for the remainder of the semester, until the final examination. After completion of the semester, the sampled students were given questionnaires to evaluate their satisfaction with pre-recorded video lectures and live ZOOM lectures on education in the Business Management field. Out of the 48 students, 27 responded to the survey, with one not consenting to the survey; thus, the total sample size came out to 26. It was sent out digitally via Google Forms and was posted on the YSCEC (online academic portal system) board, which is an academic forum for Yonsei University, for participation. The students were asked to complete the whole survey-consisting of 36 questions-anonymously. The questionnaire was purposely created for this research in order to collect the data on college students' satisfaction and participation, as well as the effectiveness of the non-face-to-face lectures. The questionnaire included questions to compare these two forms of online teaching, mainly focusing on preferences and opinions related to them. The basic information about the students, such as age, gender, and grade level, were collected. There were eleven closed-ended questions scored on a five-point scale from 'strongly agree' to 'strongly disagree' according to the following criteria: effectiveness of learning, material worth the tuition, activeness during the lecture, etc. Another set of closed-ended questions were also scored on a five-point scale to evaluate how students felt about the quality of the lectures and which technical factors hindered them from learning the materials via online learning. Finally, there were four open-ended questions that asked for the individuals to provide their thoughts about the pros and cons of learning via the two forms of instructions, as well as the factors that need improvement for the future.

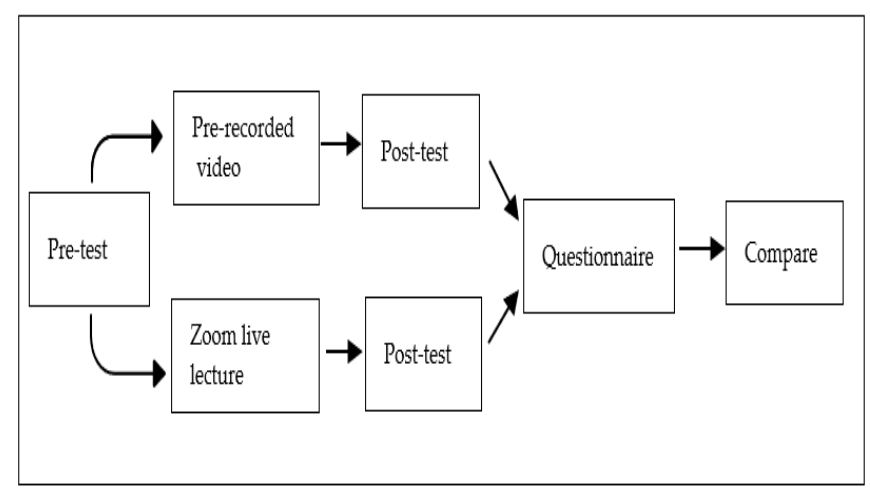

Figure 1. Flow diagram that shows the process of research. 
A statistical software called R-Programming was used for analysis of the data. R-Programming is one of the technologies that is often used for statistical data analysis. Providing a wide range of methods for statistical and graphical use, R-programming has been popularly used as a preferred option for analytics along with the SPSS program. Therefore, with this statistical data analysis program, this paper was able to obtain the results for our data. This paper tries to compare the two rising forms of online education and to see which one is more preferred and how effective it is for education. The results show that students prefer pre-recorded video lectures to live ZOOM lectures; $53.8 \%$ chose pre-recorded video lectures, $7.7 \%$ chose live ZOOM lectures, and $30.8 \%$ chose both pre-recorded and ZOOM lectures. This can be graphically seen in Figure 2. In addition, using the t-test for difference of means, the significant $p$-values for each type of instruction (see Tables 1-3 below) demonstrate that the difference between mean scores found in our sample is significantly different from the hypothesized difference, which is 0 .

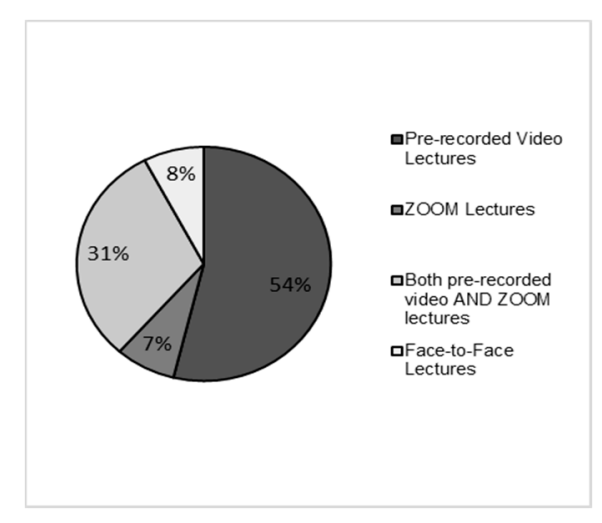

Figure 2. Which method of learning do you favor/prefer the most?

Table 1. Mean scores for each type of instruction. Learning the content: The live ZOOM lectures/ pre-recorded video lectures were helpful for learning the material/concept.

\begin{tabular}{ccc}
\hline & Zoom & Recorded \\
\hline Mean & 2.78 & 3.52 \\
Variance & 0.99 & 1.16 \\
Observations & 23 & 23 \\
\hline$p$-value (two-tailed) for difference of means $=0.018$
\end{tabular} *

Table 2. Mean scores for each type of instruction. Learning the objective: The given objectives are achievable with live ZOOM lectures/pre-recorded video lectures.

\begin{tabular}{ccc}
\hline & Zoom & Recorded \\
\hline Mean & 2.43 & 3.21 \\
Variance & 0.80 & 1.63 \\
Observation & 23 & 23 \\
\hline
\end{tabular}

Table 3. Mean scores for each type of instruction. Worth the tuition: I believe the live ZOOM lectures/pre-recorded video lectures are worth the tuition.

\begin{tabular}{ccc}
\hline & Zoom & Recorded \\
\hline Mean & 1.69 & 2.43 \\
Variance & 0.67 & 1.43 \\
Observation & 23 & 23 \\
\hline alue (two-tailed) for difference of means $=0.010$
\end{tabular} *

$p$-value (two-tailed) for difference of means $=0.010 *$. 


\section{Results}

Table 1 was based on the survey question that asked the respondents how effective the two forms of online education were to learn the material/concepts for that specific business management course. A total of $39.1 \%$ of the respondents chose 'neutral' for this question for ZOOM, which was the highest out of the choices, with 'disagree' being 30.4\% and 'agree' with 17.4\%. Pre-recorded lectures had similar results. For this question, both 'neutral' and 'agree' were 30.8\%, and 'disagree' and 'strongly agree' were also both $19.2 \%$, with no one choosing 'strongly disagree' (see Figures 3 and 4 below). From this result, though there is not too much of a difference, we can still confidently say that pre-recorded lectures are more effective when it comes to teaching students the materials.

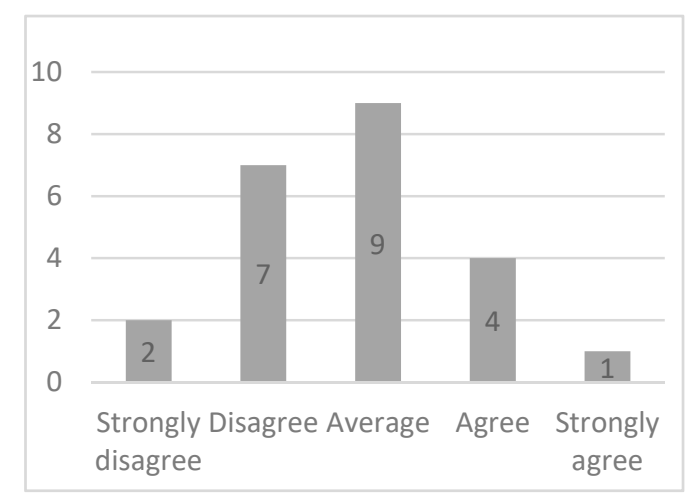

Figure 3. The ZOOM lecture was helpful for learning the material/concept.

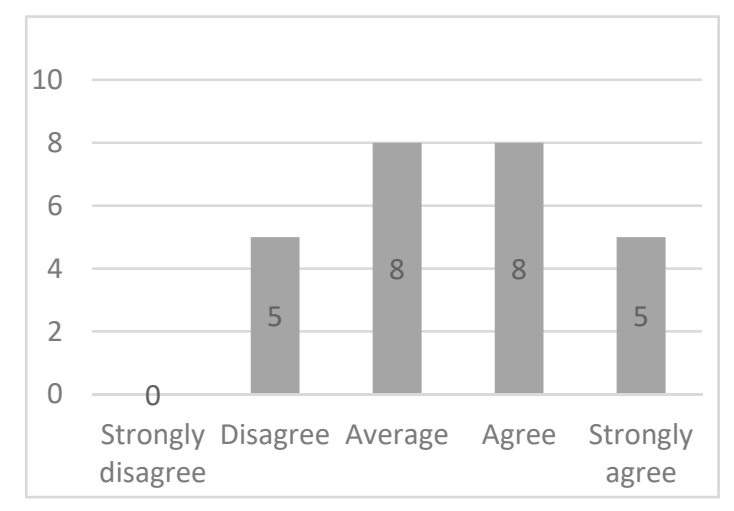

Figure 4. The pre-recorded video lecture was helpful for learning the material.

Moreover, Table 2 was based on the question that asked whether the two forms of instruction helped achieve the course objective. For ZOOM lectures, 10 (43.5\%) responded 'neutral', seven (30.4\%) responded 'disagree', four (17.4\%) said 'strongly disagree', and no one responded with 'strongly agree'. For the pre-recorded lectures, 12 (46.2\%) responded 'neutral', five (19.2\%) responded 'strongly agree', four (15.4\%) responded 'agree', three (11.5\%) responded 'strongly disagree', and, finally, two (7.7\%) responded 'disagree' (see Figures 5 and 6). In these results, there are no respondents for 'strongly agree' for ZOOM, while there are five respondents for pre-recorded lectures, which clearly demonstrates that pre-recorded lectures are preferred to ZOOM lectures because this learning format allows for class objectives/goals to be achieved.

The final table, Table 3, was based on the survey question that asked if the students thought that the two online methods of education were worth the tuition cost. In the ZOOM lecture results, 12 out of the 23 respondents who took ZOOM lectures said that they 'strongly disagree', critically indicating that more than half of the students who took ZOOM lectures felt that they were not worth the cost. For the pre-recorded lectures, eight out of the 26 students answered 'neutral' and another eight of the students chose 'strongly disagree' (see Figures 7 and 8). 


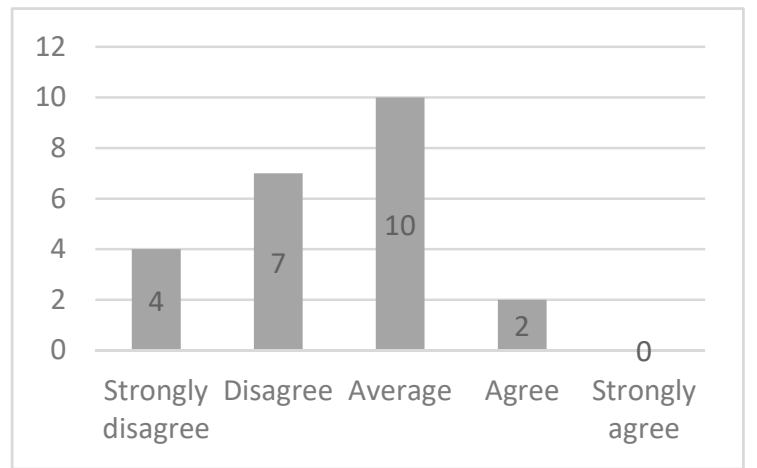

Figure 5. The given objectives are achievable with ZOOM lectures.

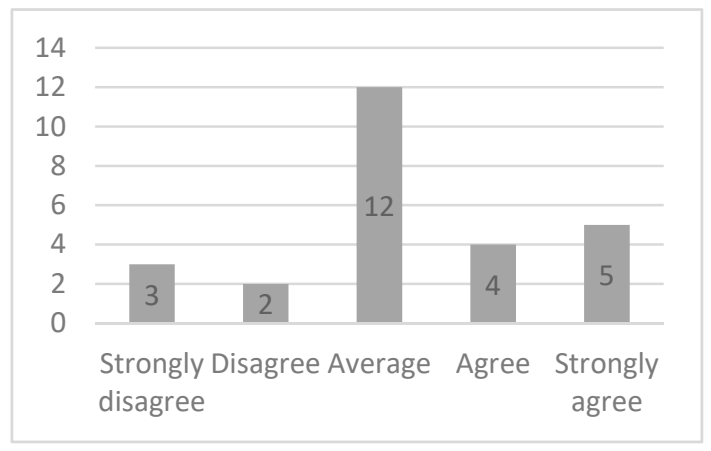

Figure 6. The given objectives are achievable with pre-recorded video lectures.

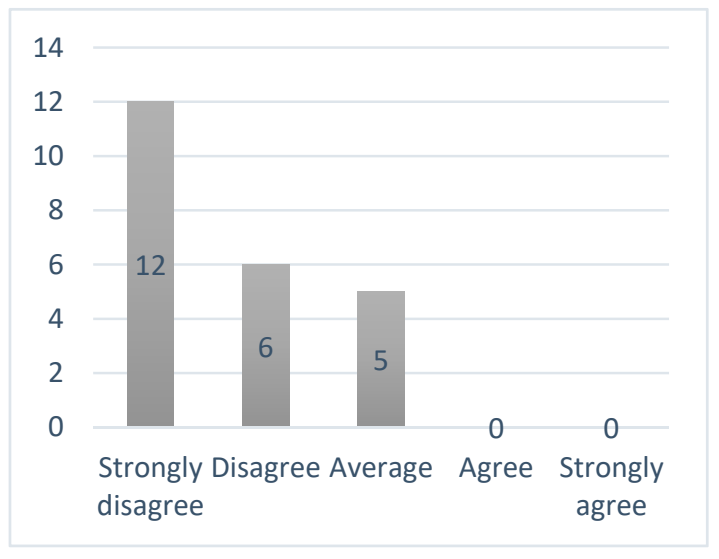

Figure 7. I believe that ZOOM lectures are worth the tuition.

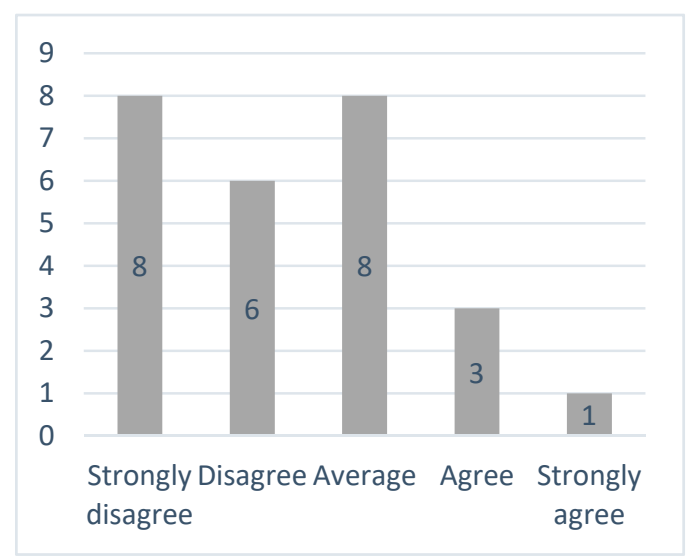

Figure 8. I believe the pre-recorded video lectures are worth the tuition. 
This result shows that though pre-recorded lectures are better than ZOOM lectures, the video lectures are financially still quite not on par with physical, face-to-face lectures; the students feel as if they are not fully getting the education that they deserve with the amount that they are paying.

Finally, Figure 9 (see below) illustrates that pre-recorded video lectures are superior to live ZOOM lectures because of their overall quality. Figure 9 is based on questions that asked the respondents how they would rate each quality of the live ZOOM lectures and the pre-recorded video lectures separately. The respondents were given a five-point scale ranging from very bad to very good, with "very bad" and "very good" being quantitatively 1 and 5, respectively. Then, the responses were averaged to get the mean.

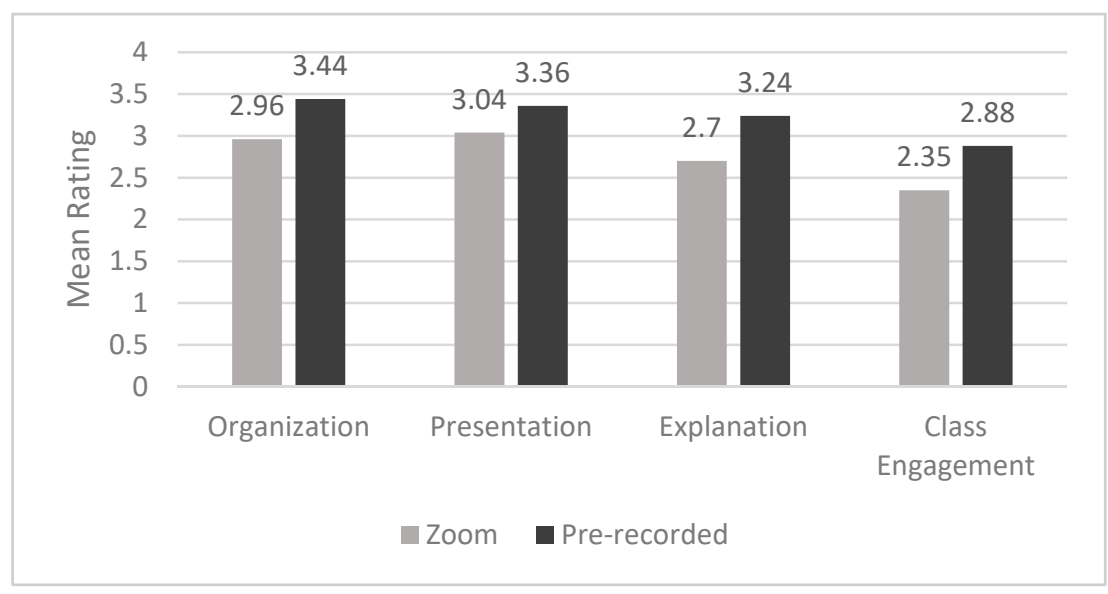

Figure 9. Mean values of ZOOM and pre-recorded video lectures.

The quality of the two online forms of education was broken into four different sections: organization, presentation, explanation, and class engagement. To evaluate for the organization quality, the students were to answer how structured and organized the lectures were. Second, the presentation quality measures if the students could clearly hear what the lectures were saying and whether the lecturers looked presentable. The explanation quality is simply whether the students think the lecturer is good at explaining the materials to the students, and, finally, the class engagement quality measures how involved the students felt in the class.

Looking at Figure 9, the results indicate that every single quality for the pre-recorded video lectures is higher compared to the live ZOOM lectures. This is consistent with the other results, further proving that the students prefer pre-recorded lectures to the ZOOM lectures.

\section{Discussion and Conclusions}

Among the 26 students who responded to our survey questions, 53.8\% responded with the answer that they prefer pre-recorded videos the most. Those who chose pre-recorded videos as the most effective way for online classes among ZOOM livestream, pre-recorded videos, face-to-face (in-person) class, or a mixed of both ZOOM livestream and pre-recorded videos did so for the following reasons.

These were some of the advantages that were mentioned by the respondents in the survey:

1. 'It's convenient. Since it's pre-recorded, you don't have to be on time for class and you can easily adjust time. Moreover, you can watch the pre-recorded videos wherever you want."

2. "It's good to be able to concentrate, plus normally, for a pre-recorded video, it comes with a ppt file or a data file, so it's more convenient and easier to concentrate."

3. "It allows you to go over what you have learned in class as much as you want. As long as the professor doesn't delete the videos, you can always revise what you have learned in class or even record the uploaded pre-recorded videos and watch them repeatedly." 
However, there were some drawbacks as well as advantages of using pre-recorded videos in class. We asked the 26 students if they had any suggestions on which parts would need to be improved to provide them with more perfect and effective lectures, and the responses were:

1. "The quality of the pre-recorded videos should be improved because it sure does affect the effectiveness."

2. "There might be some professors who simply upload a YouTube lecture that they found on the internet and call that a class, when they should actually prepare and provide a proper lecture that the students really need."

3. "Watching a pre-recorded video instead of having a real-time face-to-face lecture isn't as effective, and it is hard to concentrate on what we are learning."

4. "Using pre-recorded videos for classes makes it harder for students to contact professors about any queries."

Furthermore, there are a couple of drawbacks and limitations to our data. For one, our sample size is small, which means that there is greater variance in the differences of means, greater standard deviation, and a lack of robustness.

Moreover, our data were collected as a convenience sample in which only students at the Yonsei University Mirae Campus participated in the questionnaire. The selection of the sample for this study was from one single university, which may limit the depth of the analysis. The biggest reason for this choice was due to the lack of resources: time, distance, funding, and more. In addition, the current COVID-19 pandemic prevented physical contact with others, and many nations have enforced social distancing, which negatively affected this paper in terms of collecting the samples from a bigger population. Finally, gender could play a role when it comes to online education, and this could impact our result. The majority of our respondents were female; $73.1 \%$ were females, and the rest were males. The reason why gender could be a factor is that it is widely known that girls are generally more organized and diligent than boys. In this respect, the preference for pre-recorded video lectures could be overestimated, since girls would spend the time to diligently watch the videos from beginning to the end, while boys would rather participate in a class than sit in front of a screen and watch the lecture. Finally, the data analysis was based on t-tests, means, and frequency distributions, which were used to analyze the data and compare mean differences; hence, generalizing the research results would not be recommended. Despite the small sample in this study, the research questions were carefully designed and monitored closely, which enhanced the acceptability of this research.

In conclusion, this paper has shown that pre-recorded video lectures are preferred to live ZOOM lectures due to their flexibility, convenience, and educational effectiveness. However, learning through video lectures depends on students' motivation to get through those materials on their own. Lack of motivation and clear deadlines to watch those video lecture materials could end up in an accumulation of workload, which would be difficult to overcome before examinations. Research done by Brockfeld et al. [30] stated that video lectures for initial delivery of information would be very effective, and these may be given importance equal to that of face-to-face lectures. However, face-to-face lectures may prove to be more effective, as stated by another researcher [37]. Live lectures will provide more structured learning schedules and may help in better management of students' workload [39]. Having said that, the results of this paper clearly explained that students prefer pre-recorded video lectures over live ZOOM lectures, as students can go through the video lectures as many times as they want, which gives independence in terms of time and space. This may be because the students of South Korea are, in general, very disciplined and have positive attitudes towards learning. Many students apparently need more time to learn than some of their peers, which could be another reason for liking pre-recorded video lectures rather than ZOOM lectures.

Author Contributions: Conceptualization, M.I.; methodology, M.I.; software D.-A.K., M.K.; validation, M.I., and D.-A.K., M.K.; formal analysis, D.-A.K., M.K.; investigation, M.I.; resources, D.-A.K., M.K.; data curation, M.I., D.-A.K.; writing — original draft preparation, D.-A.K., M.K.; writing—review and editing, M.I.; visualization, M.I. All authors have read and agreed to the published version of the manuscript. 
Funding: The research received no external funding.

Conflicts of Interest: The authors declare no conflict of interest.

\section{References}

1. Fleming, N.D. VARK: A Guide to Learning Styles. Available online: www.vark-learn.com/english (accessed on 29 November 2019).

2. Callas, P.W.; Bertsch, T.F.; Caputo, M.P.; Flynn, B.S.; Doheny-Farina, S.; Ricci, M.A. Medical students' evaluations of lectures attended in person or from rural sites via interactive videoconferencing. Teach. Learn. Med. 2004, 16, 46-50. [CrossRef] [PubMed]

3. Nielsen, E.; Sheppard, M.A. Television as a patient education tool: A review of its effectiveness. Patient Educ. Couns. 1988, 11, 3-16. [CrossRef]

4. Lees, A.; Rock, W.P. A comparison between written, verbal, and videotape oral hygiene instruction for patients with fixed appliances. J. Orthod. 2000, 27, 323-328. [CrossRef] [PubMed]

5. Moore, M.G. Theory of transactional distance. In Theoretical Principles of Distance Education; Keegan, D., Ed.; Routledge: New York, NY, USA, 1997; pp. 22-38.

6. Gallien, T.; Oomen-Early, J. Personalized versus collective instructor feedback in the online classroom: Does type of feedback affect student satisfaction, academic performance and perceived connectedness with the instructor? Int. J. eLearn. 2008, 7, 463-476.

7. Plante, K.; Asselin, M.E. Best practices for creating social presence and caring behaviors online. Nurs. Educ. Perspect. 2014, 35, 219-223. [CrossRef] [PubMed]

8. Tanis, C.J. The Seven Principles of Online Learning: Feedback from Faculty and Alumni on Its Importance for Teaching and Learning. Res. Learn. Technol. 2020, 28. [CrossRef]

9. Sato, T.; Haegele, J.A. Physical educators' engagement in online adapted physical education graduate professional development. Prof. Dev. Educ. 2018, 44, 272-286. [CrossRef]

10. Morrison, D. Four-Step Strategy to Create Active Learning in Any Learning Space-Online, F2F or Blended, Online Learning Insights. 2015. Available online: https://onlinelearninginsights.wordpress.com/2015/09/0 2/four-step-strategy-to-create-active-learning-in-any-learning-space-online-f2f-or-blended/ (accessed on 4 August 2020).

11. Bertsch, T.F.; Callas, P.W.; Rubin, A.; Caputo, M.P.; Ricci, M.A. Effectiveness of lectures attended via interactive video conferencing versus in-person in preparing third-year internal medicine clerkship students for Clinical Practice Examinations (CPX). Teach. Learn. Med. 2007, 19, 4-8. [CrossRef]

12. Engilman, W.D.; Cox, T.H.; Bednar, E.D.; Proffit, W.R. Equipping orthodontic residency programs for interactive distance learning. Am. J. Orthod. Dentofacial Orthop. 2007, 131, 651-655. [CrossRef]

13. Schreiber, B.E.; Fukuta, J.; Gordon, F. Live lecture versus podcast in undergraduate medical education: A randomised controlled trial. BMC Med. Educ. Oct. 2010, 10, 68. [CrossRef]

14. Garrison, D.R.; Shale, D. Mapping the boundaries of distance education: Problems in defining the field. Am. J. Distance Educ. 1987, 1, 7-13. [CrossRef]

15. Makaza, D.; Madzima, K. The current state of e-learning at universities in Zimbabwe: Opportunities and challenges. Int. J. Educ. Dev. Using ICT 2008, 4, 34-48.

16. Svinicki, M.; McKeachie, W.J. Teaching Tips: Strategies, Research, and the Theory for College and University Teachers, 13th ed.; Wadsworth: Belmont, CA, USA, 2011.

17. Lambert, C. Twilight of the lecture. Harvard Magazine, March-April 2012; 23-27.

18. Gunn, C.; French, S.; MacLeod, H.; McSporran, M.; Conole, G. Gender issues in computer-supported learning. ALT J Assoc. Learn. Tech. J. 2002, 10, 32-44. [CrossRef]

19. Harris, J.M.; Sklar, B.M.; Amend, R.W.; Novalis-Marine, C. The growth, characteristics, and future of online CME. J. Contin. Educ. Health Prof. 2010, 30, 3-10. [CrossRef] [PubMed]

20. Romanov, K.; Nevgi, A. Do medical students watch video clips in eLearning and do these facilitate learning? Med Teach. 2007, 29, 484-488. [CrossRef] [PubMed]

21. Romanov, K.; Nevgi, A. Learning outcomes in medical informatics: Comparison of a WebCT course with ordinary web site learning material. Int. J. Med. Inform. 2006, 75, 156-162. [CrossRef] [PubMed] 
22. Allen, I.E.; Seaman, J.; Poulin, R.; Straut, T.T. Online Report Card tracking Online Education in the United States; Babson Survey Research Group and Quahog Research Group, LLC.: Wellesley, MA, USA, 2016. Available online: http://onlinelearningsurvey.com/reports/onlinereportcard.pdf.24 (accessed on 2 August 2020).

23. Helms, J.L.; Marek, P.; Randell, C.K.; Rogers, D.T.; Taglialatela, L.A.; Williamson, A.L. Developing an Online Curriculum in Psychology: Practical Advice from a Departmental Initiative. In Best Practices for Technology-Enhanced Teaching and Learning: Connecting to Psychology and the Social Sciences; Dunn, D.S., Freeman, J., Stowell, J.R., Wilson, J.H., Eds.; Oxford University Press: Cambridge, UK, 2011; pp. 53-71.

24. Kelly, R. Practical advice for going from face to face to online teaching. Online Classroom. 2010, 1, 3. Available online: www.facultyfocus.com/articles/online-education/practical-advice-for-going-from-face-to-face-to -online-teaching/ (accessed on 4 August 2020).

25. Doering, A.; Veletsianos, G.; Scharber, C.; Miller, C. Using the technological, pedagogical, and content knowledge framework to design online learning environments and professional development. J. Educ. Comp. Res. 2009, 41, 319-346. [CrossRef]

26. Benton, S.L.; Cashin, W.E. Student Ratings of Teaching: A Summary of Research and Literature; The IDEA Center: Manhattan, KS, USA, 2012.

27. Gravestock, P.; Gregor-Greenleaf, E. Student Course Evaluations: Research, Models and Trends. Toronto, Canada: Higher Education Quality Council of Ontario. 2008. Available online: http://www.heqco.ca/SiteColle ctionDocuments/Student\%20Course\%20Evaluations_Research,\%20Models\%20and\%20Trends.pdf (accessed on 1 September 2020).

28. Kite, M.E. (Ed.) Effective Evaluation of Teaching: A Guide for Faculty and Administrators; Society for the Teaching of Psychology: Washington, DC, USA, 2012.

29. Gloria, A.M.; Uttal, L. Conceptual Considerations in Moving from Face-to-Face to Online Teaching. Int. J. E-Learn. 2020, 19, 139-159.

30. Brockfeld, T.; Müller, B.; Laffolie, J.D. Video versus Live Lecture Courses: A Comparative Evaluation of Lecture Types and Results. 2018. Available online: https://www.tandfonline.com/doi/full/10.1080/10872981. 2018.1555434 (accessed on 20 May 2020).

31. Rogers, D.A.; Regehr, G.; Yeh, K.A.; Howdieshell, T.R. Computer-assisted learning versus a lecture and feedback seminar for teaching a basic surgical technique skill. Am. J. Surg. 1998, 175, 508-510. [CrossRef]

32. Brooks, P.A.; Renvall, M.J.; Bulow, K.B.; Ramsdell, J.W. A comparison between lecture and videotape in service for certified nursing assistants in skilled nursing facilities. J. Am. Med. Dir. Assoc. 2000, 1, 191-196. [PubMed]

33. Cardall, S.; Krupat, E.; Ulrich, M. Live lecture versus video-recorded lecture: Are students voting with their feet? Acad. Med. 2008, 83, 1174-1178. [CrossRef]

34. Haney, M.; Silvestri, S.; Van Dillen, C.; Ralls, G.; Cohen, E.; Papa, L. A comparison of tele-education versus conventional lectures in wound care knowledge and skill acquisition. J. Telemed. Telecare. 2012, 18, $79-81$. [CrossRef] [PubMed]

35. Martin, N.; Lazalde, O.M.; Stokes, C.; Romano, D. An evaluation of remote communication versus face-to-face in clinical dental education. Br. Dent. J. 2012, 6, 277-282. [CrossRef]

36. Ramlogan, S.; Raman, V.; Sweet, J. A Comparison of Two Forms of Teaching Instruction: Video vs. Live Lecture for Education in Clinical Periodontology. 2013. Available online: https://onlinelibrary.wiley.com/doi/ 10.1111/eje.12053 (accessed on 16 May 2020).

37. Mayer, R. Multimedia Learning; Cambridge University Press: Cambridge, UK, 2001.

38. Maag, M. iPod, uPod? An emerging mobile learning tool in nursing education and students' satisfaction. In Procedeengs of the 23rd Annual Ascilite Conference, Sidney, Australia, 28 November 2006.

39. Ranasinghe, L.; Wright, L. Video lectures versus live lectures: Competing or complementary? Med. Educ. Online 2019, 24, 1574522. [CrossRef] [PubMed]

(C) 2020 by the authors. Licensee MDPI, Basel, Switzerland. This article is an open access article distributed under the terms and conditions of the Creative Commons Attribution (CC BY) license (http://creativecommons.org/licenses/by/4.0/). 